\title{
Mycobacteria Manipulate G-Protein- Coupled Receptors to Increase Mucosal Rac1 Expression in the Lungs
}

\author{
Nader Alaridah ${ }^{a}$ Nataliya Lutay ${ }^{\mathrm{a}}$ Erik Tenland $^{\mathrm{a}}$ Anna Rönnholm ${ }^{\mathrm{a}}$ \\ Oskar Hallgren $^{\mathrm{b}}$ Manoj Puthia ${ }^{\mathrm{a}}$ Gunilla Westergren-Thorsson ${ }^{\mathrm{c}}$ \\ Gabriela Godaly ${ }^{a}$ \\ ${ }^{a}$ Division of Laboratory Medicine, Department of MIG, ${ }^{b}$ Division of Clinical Sciences, Department of Respiratory \\ Medicine and Allergology, and ' Division of Vascular- and Respiratory Research Unit of Lung Biology, Department of \\ Experimental Medical Science, Lund University, Lund, Sweden
}

\section{Key Words}

G-protein-coupled receptors · Bacille Calmette-Guérin ·

Pulmonary tuberculosis

\begin{abstract}
Mycobacterium bovis bacille Calmette-Guérin (BCG) is currently the only approved vaccine against tuberculosis (TB). BCG mimics $M$. tuberculosis (Mtb) in its persistence in the body and is used as a benchmark to compare new vaccine candidates. BCG was originally designed for mucosal vaccination, but comprehensive knowledge about its interaction with epithelium is currently lacking. We used primary airway epithelial cells (AECs) and a murine model to investigate the initial events of mucosal BCG interactions. Furthermore, we analysed the impact of the G-protein-coupled receptors (GPCRs), CXCR1 and CXCR2, in this process, as these receptors were previously shown to be important during TB infection. BCG infection of AECs induced GPCR-dependent Rac1 up-regulation, resulting in actin redistribution. The altered distribution of the actin cytoskeleton involved the MAPK signalling pathway. Blocking of the CXCR1 or CXCR2 prior to
\end{abstract}

infection decreased Rac1 expression, and increased epithelial transcriptional activity and epithelial cytokine production. BCG infection did not result in epithelial cell death as measured by $\mathrm{p} 53$ phosphorylation and annexin. This study demonstrated that BCG infection of AECs manipulated the GPCRs to suppress epithelial signalling pathways. Future vaccine strategies could thus be improved by targeting GPCRs.

(c) 2016 The Author(s)

Published by S. Karger AG, Basel

\section{Introduction}

It has been proposed that mucosal delivery of the bacille Calmette-Guérin (BCG) vaccine provides superior protection against tuberculosis (TB), a disease that kills 1.9 million people each year $[1,2]$. Traditionally, the adaptive immune responses, particularly central memory CD4+ and CD8+ cells, are considered to be important for long-term immunity [3-6]. However, emerging evidence indicates that the cells of the innate immune system are equipped with "epigenetic memory" where genes encoding specific host defence molecules increase the response

\section{KARGER}

E-Mail karger@karger.com www.karger.com/jin

\section{2016 The Author(s) \\ Published by S. Karger AG, Basel \\ Karger}

This article is licensed under the Creative Commons AttributionNonCommercial-NoDerivatives 4.0 International License (CC BYNC-ND) (http://www.karger.com/Services/OpenAccessLicense) Usage and distribution for commercial purposes as well as any distribution of modified material requires written permission.
Dr. Gabriela Godaly

Division of Laboratory Medicine, Department of MIG, Lund University Sölvegatan 23

SE-221 00 Lund (Sweden)

E-Mail Gabriela.godaly@med.lu.se 
upon re-stimulation [4-7]. Recent studies further demonstrated that airway epithelial cells (AECs) harbour $M y$ cobacterium tuberculosis (Mtb) and are critical during the progression to active disease $[8,9]$. These cells could thus be important for both host defence and vaccine development, but a more comprehensive knowledge of direct interaction between AECs and mycobacteria is currently lacking [10].

BCG mimics Mtb in its ability to persist in the body, and is similar to the tubercle bacillus in its physiological, molecular, and metabolic responses [11-14]. This invasive bacterium actively induces its own uptake by macropinocytosis to enter normally non-phagocytic cells such as AECs [15]. Until now, Toll-like receptor (TLR)2, TLR4 and C-type lectins have been implicated in mycobacteria-induced epithelial signalling and uptake $[16,17]$. It has also been observed that mycobacteria manipulate epithelial production of the cytokine CXCL8 through the inhibitory G-protein-coupled receptor (GPCR) kinase 2 [18]. To trigger GPCR signal transduction in AECs, intracellular bacteria, such as Shigella, are known to engage GTPases in actin polymerization [19-21]. These low-molecular-weight proteins belong to the Ras GTPase superfamily and include Rab and Rho/Rac, with the ability to act as molecular switches by coupling extracellular signals to different cellular responses, cytoskeletal integrity, intracellular vesicular transport, and trafficking of proteins [22]. Inhibition of Rac1 was recently shown to repeal tumour protein $\mathrm{p} 53$ suppression of STAT and NF- $\mathrm{kB}$, and Rho is essential in the establishment and maintenance of tight junctions [23]. Previous studies indicate that signalling through TLRs is important for the phagocytosis of bacteria, as TLR-mediated MyD88-dependent activation of p38 is required for phagosome maturation [24, 25]. Intracellular pathogens such as Listeria monocytogenes manipulate TLRs through the MAPK pathway to avoid phagosome maturation and autophagy $[26,27]$. The p53 pathway acts in synergy with the p38 MAPK pathway to mediate cell cycle arrest, cellular senescence and apoptosis [28].

The innate host defence of the conducting airway depends on the multiple barriers created by layers of mucus and the tight adhesions between epithelial cells. In the human lung, AECs are able to harbour Mtb and are critical during progression to active disease [29]. Recently, mucosal vaccination with an attenuated Mtb strain induced a strong innate immune response, followed by a robust central memory answer [30]. AECs facilitate a protective environment for Mtb replication where it could gain enhanced virulence by modifying envelope structure and gene expression [31]. AECs also interact with other cells of the innate immune system, such as granulocytes, monocytes, macrophages, and innate lymphoid cells, to mount an effective defence against the invading pathogen as well as to activate the following specific immunity. AECs are now recognized as active participants of the immune response against Mtb [32]. In this study, we analysed mycobacteria-induced epithelial signalling pathways and the contribution of GPCRs to further elucidate these responses. We could conclude that BCG induced Rac1 up-regulation, resulting in long-term actin cytoskeleton distribution. Inhibition of GPCRs decreased BCGinduced Rac1 expression but increased AEC transcriptional activity and epithelial cytokine production.

\section{Material and Methods}

\section{Ethical Statement}

The Swedish Research Ethical Committee in Lund (FEK $413 / 2008$ ) approved the isolation of the primary AECs. These were acquired from lung explants of healthy donors with irreversible brain damage and no history of lung disease; the lungs were intended for transplantation, but could instead be used in this study as no matched recipients were available at that moment. Written consent was obtained from the donors' closest relatives. The murine study was approved by the Animal Experiment Ethics Committee at the Lund District Court in Sweden (M7-15).

\section{Bacterial Strain and Growth Condition}

Mycobacterium bovis BCG Montreal strain containing the pSMT1 shuttle plasmid was prepared as previously described [33]. Briefly, the mycobacteria were grown in Middlebrook 7H9 broth, supplemented with 10\% ADC enrichment (Becton Dickinson, Oxford, UK) and hygromycin (50 mg/L; Roche, Lewes, UK), the culture was washed twice with sterile PBS, re-suspended in broth, and then dispensed into vials. Glycerol was added to a final concentration of $25 \%$ and the vials were frozen at $-80^{\circ} \mathrm{C}$. Prior to each experiment, a vial was defrosted, added to $9 \mathrm{~mL}$ of $7 \mathrm{H} 9 / \mathrm{ADC} /$ hygromycin medium, and incubated with shaking for $72 \mathrm{~h}$ at $37^{\circ} \mathrm{C}$. Mycobacteria were then centrifuged for $10 \mathrm{~min}$ at $3,000 \mathrm{~g}$, washed twice with PBS, and re-suspended in $10 \mathrm{~mL}$ of PBS.

\section{Cell Culture}

Bronchial tissue was dissected from lungs and kept in Dulbecco's modified Eagle's medium (DMEM) supplemented with gentamicin, penicillin, streptomycin, Fungizone, and 10\% FCS (all from Gibco, Paisley, UK) until further isolation. After removing intraluminal mucus and surrounding tissue, bronchi were digested in $0.1 \%$ protease (Sigma, St. Louis, MO, USA) prepared in a minimum essential medium Eagle, Spinner modification (SigmaAldrich) supplemented with gentamicin, penicillin, streptomycin, and Fungizone for $24 \mathrm{~h}$. The cells were recovered by repeated intraluminal rinsing with DMEM supplemented as above. Cells were filtered through a 100- $\mu \mathrm{m}$ strainer (Falcon, Becton Dickinson) and seeded in cell-culture flasks coated with $1 \%$ collagen-1 (PureCol, Inamed Biomaterial, Freemont, CA, USA) in bronchial epithelial 
cell growth medium (Clonetics). The following day, cells were thoroughly washed with a medium change every other day. Experiments were performed in passage 3 or 4 .

\section{Incubation of AECs with Mycobacteria}

AECs were grown in 6-well plates $\left(2.0 \times 10^{5}\right.$ cells/well; Fisher Scientific, Loughborough, UK) for 2 days until confluent (80\%). Before the experiment, the medium was changed and the cells were treated with monoclonal mouse anti-human CXCR1 and/or monoclonal mouse anti-human CXCR2 antibodies $(10 \mu \mathrm{g} / \mathrm{mL}$; R\&D Systems) and/or Rac1 inhibitor ( $50 \mu \mathrm{M}$; Merck Millipore) for 30 min on ice, followed by infection with BCG. The cells were infected with a multiplicity of infection (MOI) of $1: 1$ at $37^{\circ} \mathrm{C}$ for up to 3 days. As a control, we used uninfected cells treated with CXCR1, CXCR2 antibodies, or the Rac1 inhibitor.

\section{Western Blot}

The primary cells were washed with PBS containing $0.2 \mathrm{mM}$ phenylmethylsulfonyl fluoride, $1 \mu \mathrm{g} / \mathrm{mL}$ pepstatin $\mathrm{A}$, and $5 \mu \mathrm{g} / \mathrm{mL}$ leupeptin (Sigma-Aldrich), and then lysed with modified mammalian protein extraction reagent solution (50 mM HEPES, 150 mM NaCl, 2 mM EDTA, 50 mM ZnCl, 1\% NP-40, 0.1\% deoxycholate, $0.1 \%$ SDS; Pierce) containing phosphatase and complete protease inhibitor cocktail $(1: 100)$. The cells were then placed on a shaker for $5 \mathrm{~min}$, collected, and then centrifuged at 10,000 $\mathrm{g}$ for 5 min. Protein samples were used immediately for Western blot analysis or stored at $-80^{\circ} \mathrm{C}$. Protein levels were measured with a NanoDrop ${ }^{\mathrm{TM}} 8000$ spectrophotometer using the Pierce $660 \mathrm{~nm}$ assay (Thermo Scientific). Medium alone and only BCG-infected cells were used as controls. Protein samples were mixed with PBS, $4 \times$ NuPAGE LDS sample buffer (Life Technologies), and $0.1 \mathrm{M}$ DTT, and incubated at $90^{\circ} \mathrm{C}$ for $10 \mathrm{~min}$ followed by centrifugation at $218 \mathrm{~g}$ for $5 \mathrm{~min}$. Equal amounts of protein $(20 \mu \mathrm{g} /$ well $)$ were loaded on a NuPAGE 4-12\% Bis-Tris Gel (Life Technologies) and separated by SDS-PAGE. A molecular weight marker (Novex ${ }^{\circledR}$ Sharp Prestained; Life Technologies) was loaded onto each gel for protein-band identification. After separation, the proteins were transferred to a PVDF membrane (GE Healthcare, Little Chalfont, UK). The membrane was then blocked with either 5\% dry milk (Santa Cruz Biotechnology, Santa Cruz, CA, USA) or 5\% BSA (Santa Cruz Biotechnology) for $1 \mathrm{~h}$ on a shaker at room temperature. Membranes were then incubated on a shaker overnight at $4^{\circ} \mathrm{C}$ with mouse monoclonal antibodies against human Racl (1: 500; 23A8 Millipore), Rho A (1:500; 26c4; Santa Cruz Biotechnology), Rab4 (1:500; 46-K; Santa Cruz Biotechnology) and goat polyclonal against human actin (1:500; I-19; Santa Cruz Biotechnology). Bound primary antibodies were detected with goat-antimouse IgG horseradish peroxidase (HRP) or rabbit-anti-goat IgG HRP (1:5,000; Santa Cruz Biotechnology) using ECL (GE Healthcare) and GelDoc equipment (Bio-Rad Laboratories). The housekeeping protein GAPDH was used to confirm equal loading on the wells. Blot intensity was quantified using ImageJ v1.49, and normalized against GAPDH. If required, membranes were stripped with Restore Western Blot stripping buffer (Pierce, Rockford, IL, USA), blocked, and re-probed with new antibodies.

\section{Phospho-Kinase Array}

A proteome human phospho-kinase array kit (Proteome Prolifer Array, R\&D Systems), a membrane-based sandwich immunoassay, was used to measure protein phosphorylation. The assay was performed according to the manufacturer's instructions. Briefly, total cell extracts were prepared from stimulated near-confluent cultures of AECs grown in 6-well plates. Untreated cells were used as controls. The cell extracts containing $500 \mu \mathrm{g}$ of total protein were incubated with the human phospho-kinase array. The proteins present in a lysate sample were captured by discrete antibodies printed in duplicate across the nitrocellulose membranes. The array was washed 3 times with $1 \times$ wash buffer for 10 min on a rocking platform shaker to remove unbound proteins. Washing was followed by incubation with a cocktail of biotinylated detection antibodies (monoclonal anti-human of phosphorylated PYK2 (Y402), MEK1/2 (S218/S222, S222/S226), JNK pan (T183/Y185, T221/Y223), p38, p53 (S15), p53 (S46), p53 (S392), STAT1 (Y701), STAT5b (Y699), STAT6 (Y641), and a subsequent addition of streptavidin-HRP conjugate. The signals were detected with the ECL Plus Western blotting detection system (GE Healthcare). Developed signals were analysed using ImageJ v1.49 analysis software.

\section{Detection of Apoptosis and Necrosis}

After incubation of AECs with BCG, the cells were detached by EDTA for about $5 \mathrm{~min}$ at room temperature, followed by the addition of a trypsin inhibitor, washed twice in PBS for 5 min $(1,000$ rpm), and stained with annexin V-Alexa Fluor ${ }^{\circledR} 488$ (1:100; Life Technologies Europe BV, Stockholm, Sweden) for $15 \mathrm{~min}$ in the dark on ice to detect early apoptosis and 7-aminoactinomycin D (1:100; BD Via-Probe, BD Pharmingen Biosciences, San Diego, CA, USA) for $15 \mathrm{~min}$ in the dark on ice to test for late apoptosis and necrosis. Mean fluorescence intensity was analysed by flow cytometry (Accuri, Becton Dickinson).

\section{Murine BCG Infection}

Male BALB/c mice, aged 8-10 weeks, were obtained from Jackson Laboratories (Bar Harbor, ME, USA). They were maintained in the animal facilities at the Department of Microbiology, Immunology, and Glycobiology, Lund University, Lund, Sweden. They were anaesthetized by isoflurane inhalation for 10-20 s. The mice were divided into 2 groups: BCG infected $(n=5)$ and uninfected $(n=3)$. For infections, BCG at $5 \times 10^{4} \mathrm{CFU}$ in $10 \mu \mathrm{L}$ PBS was given intranasally, and $10 \mu \mathrm{L}$ PBS was given to the control mice. After 5 weeks, the mice were sacrificed by intraperitoneal administration of pentobarbitone $(60 \mathrm{mg} / \mathrm{mL}, 0.05-0.1 \mathrm{~mL} /$ mice $)$. The largest lobe was saved in paraformaldehyde (4\%), and used for immunohistochemistry staining. Remaining lobes were homogenised and plated on $7 \mathrm{H} 11$ agar plates and incubated at $37^{\circ} \mathrm{C}$ for 4 weeks for $\mathrm{CFU}$ measurements.

\section{Immunofluorescence Microscopy}

The expression of actin and Rac in the sections of lung tissue from BCG-infected BALB/c mice was detected by immunofluorescence staining. The fixed tissue samples were dehydrated by overnight incubation in ethanol, followed by xylene, and placed in Histowax (Histolab Products, VästraFrölunda, Sweden), according to the manufacturer's recommendations. The samples were embedded in paraffin; sections $(4-5 \mu \mathrm{m})$ were cut and placed on glass slides. Deparaffinization, rehydration, and antigen retrieval of the specimens were done, followed by blocking in 10\% FCS with $1 \%$ BSA in TBS for $2 \mathrm{~h}$ at room temperature, followed by incubation overnight, shaking in a cold room with PBS with $1 \%$ BSA; the goat polyclonal anti-actin (sc-1616) (Santa Cruz Biotechnology) or 


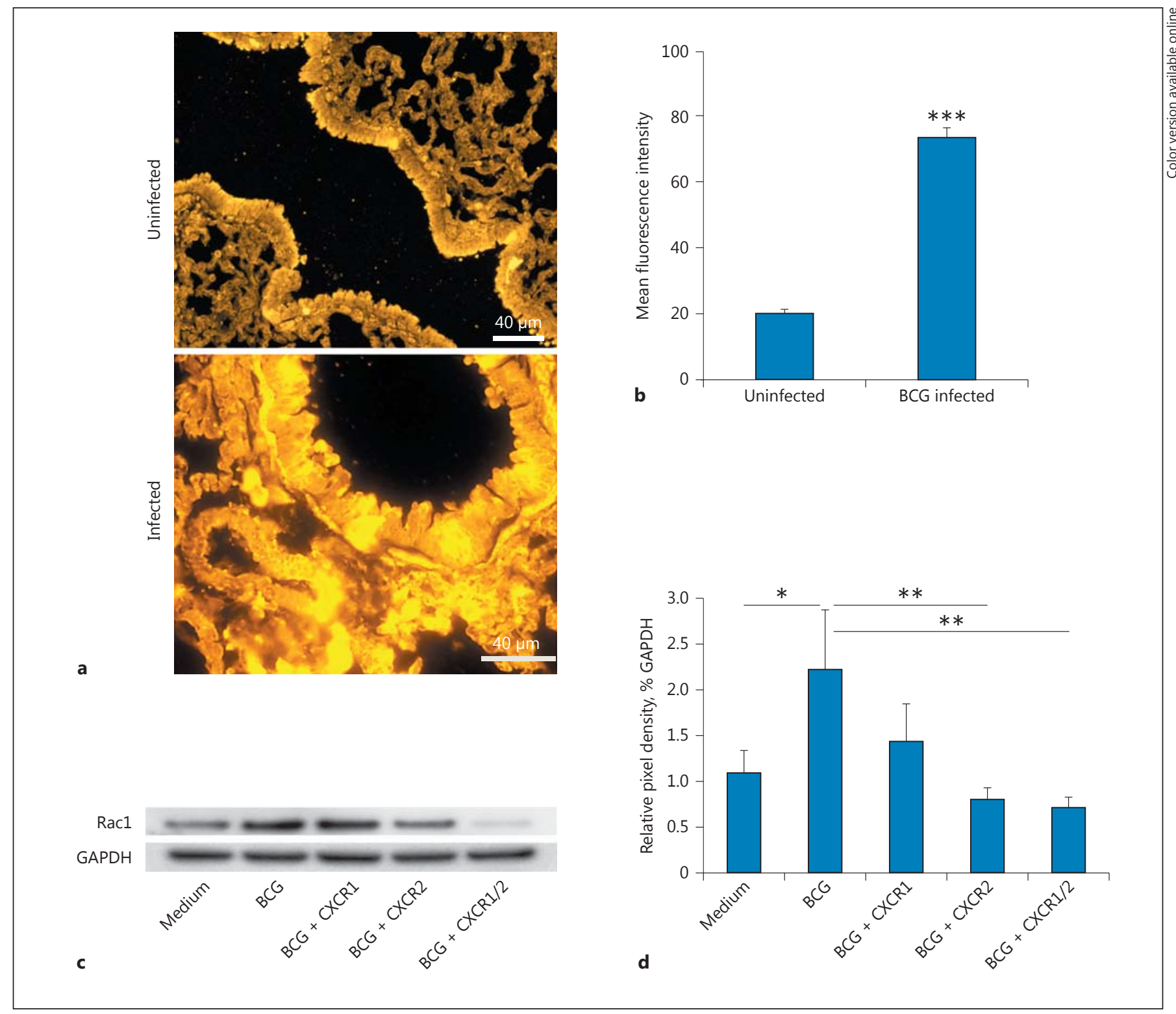

Fig. 1. Mycobacteria increase Rac1 expression. The impact of BCG infection, CXCR1 and CXCR2 on modulated epithelial Rac1 expression was studied in a murine model and by Western blot. a, b Mycobacterial infection significantly altered Rac1 expression in vivo as detected by immunofluorescence microscopy compared

mouse monoclonal antibody against Rac1clone 23A8 (Millipore) antibodies were used. As a control, we used an isotype antibody by replacing the primary antibody with antibody diluent (blocking buffer). The specimens were washed twice with PBS plus $0.0025 \%$ Triton X-100 for $5 \mathrm{~min}$, and then incubated with fluorophore-conjugated rabbit anti-goat or goat anti-mouse secondary antibody (1: 2,000; Invitrogen) in PBS with 1\% BSA for $2 \mathrm{~h}$ in the dark. Slides were then examined by fluorescence microscopy (AX60, Olympus Optical).

Increased Mucosal Rac1 Expression in TB to uninfected mice. c, d BCG infection increased epithelial Rac1 expression, but CXCR1/2 blocking prior to infection decreased Rac1. Data are presented as representative images or as mean \pm SEM of 3 separate experiments. ${ }^{*} p<0.05$; $^{* *} p<0.01$; $^{* * *} p<0.001$.

For in vitro actin expression, AECs were seeded on glass slides $(12 \mathrm{~mm} \varnothing)$, and allowed to attach for 1 day at $37^{\circ} \mathrm{C}$ in a $5 \% \mathrm{CO}_{2}$ atmosphere. Racl inhibitor was added for $30 \mathrm{~min}$ on ice before BCG infection. Bacteria were added to the AECs at MOI 1:1, and incubated for $72 \mathrm{~h}$, followed by fixation in $4 \%$ paraformaldehyde. The glass slides were washed twice in PBS with 5\% FCS, and blocked and mounted overnight with CytoPainter PhalloidiniFluor 488 Reagent (Abcam) and anti-Mtb antibody (ab905; 1:200; Abcam).

J Innate Immun 2017;9:318-329 


\section{ELISA}

IL-6 (D6050) and IL-10 (D1000B) secretion by the infected cells was quantified in supernatants by human quantikine ELISA kits (R\&D Systems) according to the manufacturer's instructions. NF- $\kappa B$ (EK1111) and AP-1 (c-Jun, EK1041) were quantified with nuclear extraction kits containing ELISA kit according to manufacturer's instructions (Affymetrix Panomics, UK).

\section{Statistical Analysis}

Prism $6 \mathrm{f}$ for Mac OS X was used for statistical analysis. The statistical difference between two groups was investigated by means of the nonparametric Mann-Whitney $U$ test. Multiple comparisons were done by one-way analysis of variance followed by the Kruskal-Wallis test with the Bonferroni correction and the Dunnett post hoc test. Significance was accepted at $p<0.05, p<0.01$, or $p<0.001$.

\section{Results}

Mycobacteria Utilize CXCR1 and CXCR2 to Induce Epithelial Rac1 Activation

Rac1, a member of the Ras superfamily of small GTPases, regulates the basal level of actin assembly and the reorganization of the actin cytoskeleton in response to GPCR stimulation [34]. BCG-induced mucosal Rac1 expression was analysed in vivo by immunohistochemistry staining of mycobacteria-infected mouse lung sections (Fig. 1a). BCG infection induced sustained mucosal Racl expression 5 weeks after infection $(p=0.0001$; Fig. 1a). We confirmed that BCG infection of primary AECs increased Racl, compared to uninfected cells ( $p=$ 0.015; Fig. 1c, d). Blocking of CXCR1 or CXCR2 decreased Rac1 production down to basal levels $(p=0.092$, $p=0.001$, and $p=0.001$ for CXCR1, CXCR2, and CXCR1/2, respectively; Fig. 1c, d).

\section{Mycobacteria Up-Regulate Actin Distribution}

During inflammation, actin cytoskeletal changes regulate junctional integrity leading to disturbed barrier function [35]. Actin expression of BCG-infected AEC was studied by Western blot and immunofluorescence (Fig. 2a, b). BCG infection induced increased actin expression compared to uninfected cells ( $p=0.002$; Fig. 2a). Blockage of the CXCR2 decreased BCG-induced actin production $(p=0.07, p=0.001$, and $p=0.006$ for CXCR1, CXCR2, and Rac1 inhibition respectively; Fig. 2a). With immunofluorescence, we observed that BCG infection induced epithelial actin redistribution (Fig. 2b; online suppl. Fig. 2; for all online supplementary material, see www.karger.com/doi/10.1159/000453454). To confirm that BCG infection regulates actin expression and distri- bution in vivo, lung tissues from BCG-infected mice were stained for actin cytoskeletal changes (Fig. 2c, d). Compared to in the uninfected animals, BCG infection increased sustained actin up-regulation for 5 weeks after infection (Fig. 2d).

\section{Mycobacteria Activate the Epithelial MAPK}

\section{Pathway}

Previous studies indicated that mycobacteria regulate the epithelial inflammatory response through GPCR kinases [18]. GPCR-mediated signalling is further known to activate the pathways of major kinases, including MAPK and JNK, new targets in drug discovery [36]. To investigate mycobacterial epithelial kinase activation, we used the human phospho-kinase array on primary AECs (Fig. 3). Mycobacterial infection led to increased epithelial phosphorylation of PYK2 $(p=$ $0.0045 ; p=0.0003)$, p38 kinase $(p=0.0001 ; p=0.0005)$ and MEK1/2 (MAP2K1/2; $p=0.0003 ; p=0.0015)$ compared to medium control at both 6 and $72 \mathrm{~h}$ after infection (Fig. 3). In contrast, JNK had decreased after $6 \mathrm{~h}$, and increased after $72 \mathrm{~h}$, compared to the control (Fig. 3). Actin distribution requires p38 and MEK1/2, and both of these molecules were activated by BCG infection of AECs (Fig. 3).

\section{Mycobacterial Induction of p53 Does Not Affect \\ Epithelial Survival}

Intracellular bacteria trigger actin polymerization in AECs by engaging GTPases such as Rac and Rab [20, 37, 38]. Inhibition of Racl was recently shown to abolish tumour protein p53 suppression of the transcription factors STAT and NF- $\kappa$ B [23]. We investigated the mycobacterial influence on epithelial p53 with a phosphorylation assay (Fig. 4). BCG infection of AECs had increased the phosphorylation of p53 at the regulatory S319 and apoptotic S46 domains, at 6 and $72 \mathrm{~h}$ post infection, but not at the $\mathrm{S} 15$ domain, which activates transcription and cell survival. Rac1 inhibition prior to infection decreased p53 (S392 and S46), possibly suggesting that Rac1 is involved in transcription and cell survival (online suppl. Fig. 1).

To analyse if mycobacteria induced cellular death, we measured epithelial apoptosis and necrosis (data not shown). We found that mycobacteria did not affect epithelial survival.

\section{BCG Manipulate Epithelial STAT Phosphorylation}

Compared to our observation using BCG, pathogenic mycobacteria are known to suppress the MAPK and JAK/ 

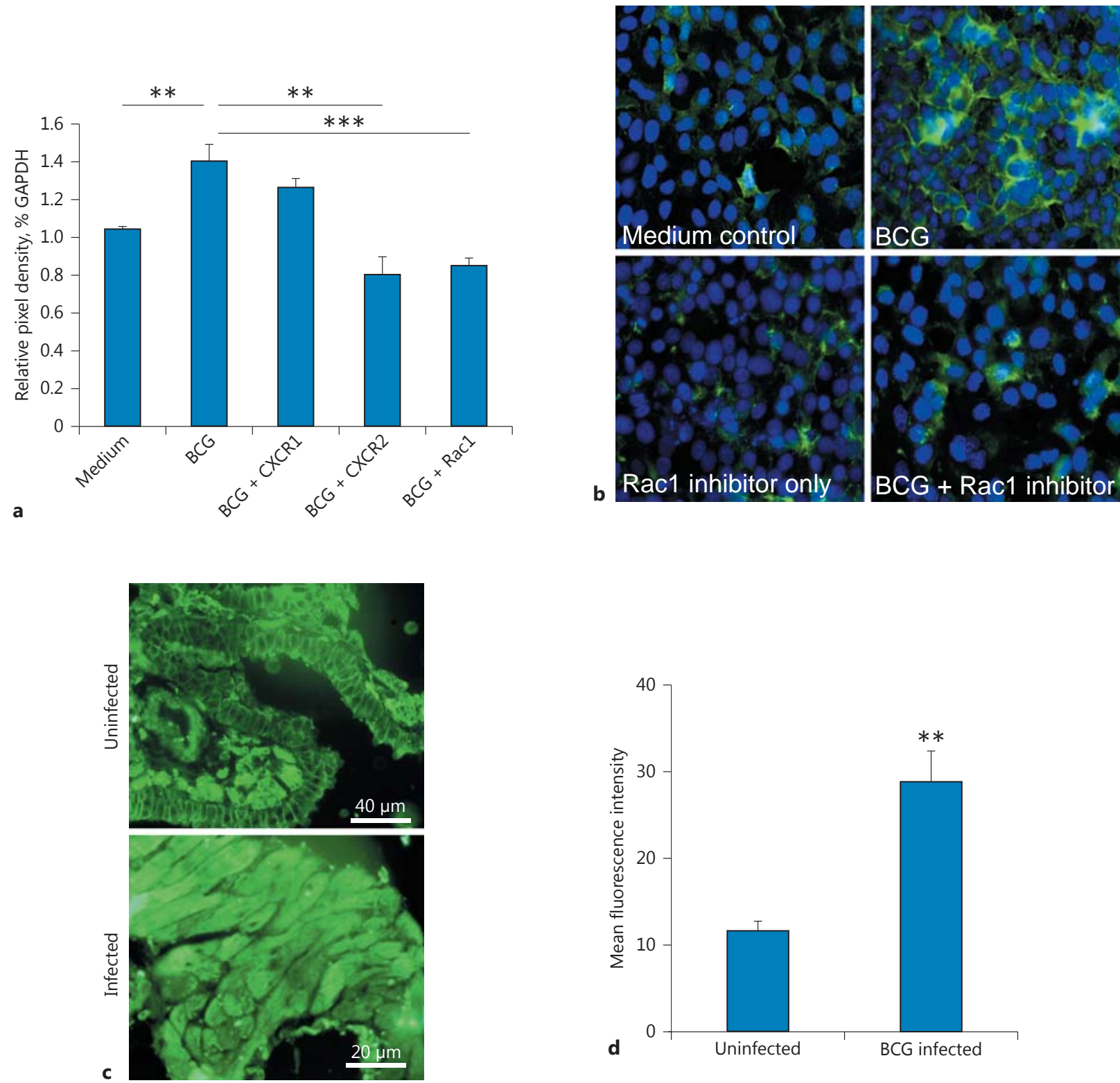

Fig. 2. Mycobacteria up-regulate actin distribution. a, b BCG-induced increased actin expression was detected in BCG-infected AECs. CXCR2 blocking or the addition of Rac1 inhibitor prior to infection decreased the actin expression. c In vivo, the infection increased actin distribution in the BCG-infected mice compared

STAT signalling pathways that are crucial for many innate and adaptive immune responses [36]. Patients with disseminated BCG infection have been found to have dominant-negative mutations in STAT1 that affect IFN $\gamma$ signalling [39]. BCG infection in primary AECs reduced to the uninfected controls, visualised by immunofluorescence microscopy. $\mathbf{d}$ The images were further analysed by ImageJ software. Data are presented as representative images or as mean \pm SEM of 3 separate experiments. ${ }^{* *} p<0.01 ;{ }^{* * *} p<0.001$.

the phosphorylation of STAT1 (Y701), STAT5b (Y699), and STAT6 (Y641) $6 \mathrm{~h}$ after infection, and increased phosphorylation on STAT1 (Y701) and STAT5b (Y699) at $72 \mathrm{~h}$ after infection, but the STAT6 (Y641) levels were reduced (Fig. 4). 
Fig. 3. Mycobacteria activate the epithelial MAPK pathway. We used BCG to investigate epithelial kinase modulation using the human phospho-kinase array. Mycobacterial infection led to increased epithelial phosphorylation of PYK2, p38 kinase, and MEK1/2 (MAPK1/2) compared to medium control 6 and $72 \mathrm{~h}$ after infection. JNK had decreased after $6 \mathrm{~h}$ but increased after $72 \mathrm{~h}$ compared to the control. Data are presented as mean \pm SEM of 3 experiments. *** $p<0.001$.

Fig. 4. Mycobacteria modulate epithelial p53 and STAT pathways. Mycobacterial influence on epithelial p53 and STAT was investigated with the phosphorylation assay. BCG infection of primary AECs increased the phosphorylation of p53 at the regulatory S319 and apoptotic S46 domains, 6 and $72 \mathrm{~h}$ after infection. In contrast, the phosphorylation at S15, which activates transcription and cell survival, was not induced by the infection. STAT1 (Y701), STAT5b (Y699), and STAT6 (Y641) were suppressed $6 \mathrm{~h}$ after infection, while BCG induced phosphorylation of STAT1 (Y701) and STAT5b (Y699) $72 \mathrm{~h}$ after infection. STAT6 (Y641) levels remained reduced during the study. Data are presented as mean \pm SEM of 3 separate experiments. ${ }^{*} p<0.05,{ }^{* *} p<0.01$; ${ }^{* * *} p<$ 0.001 .
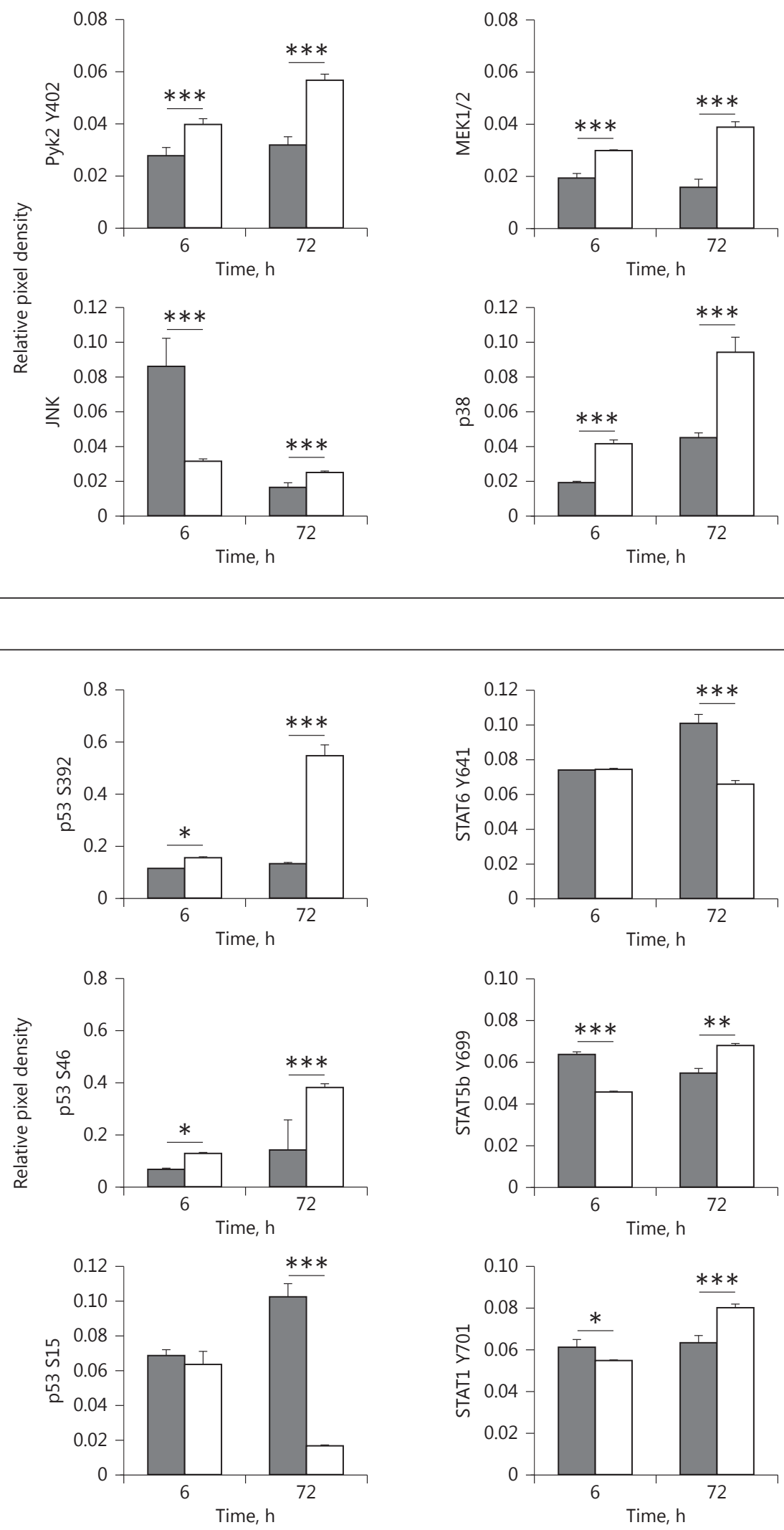


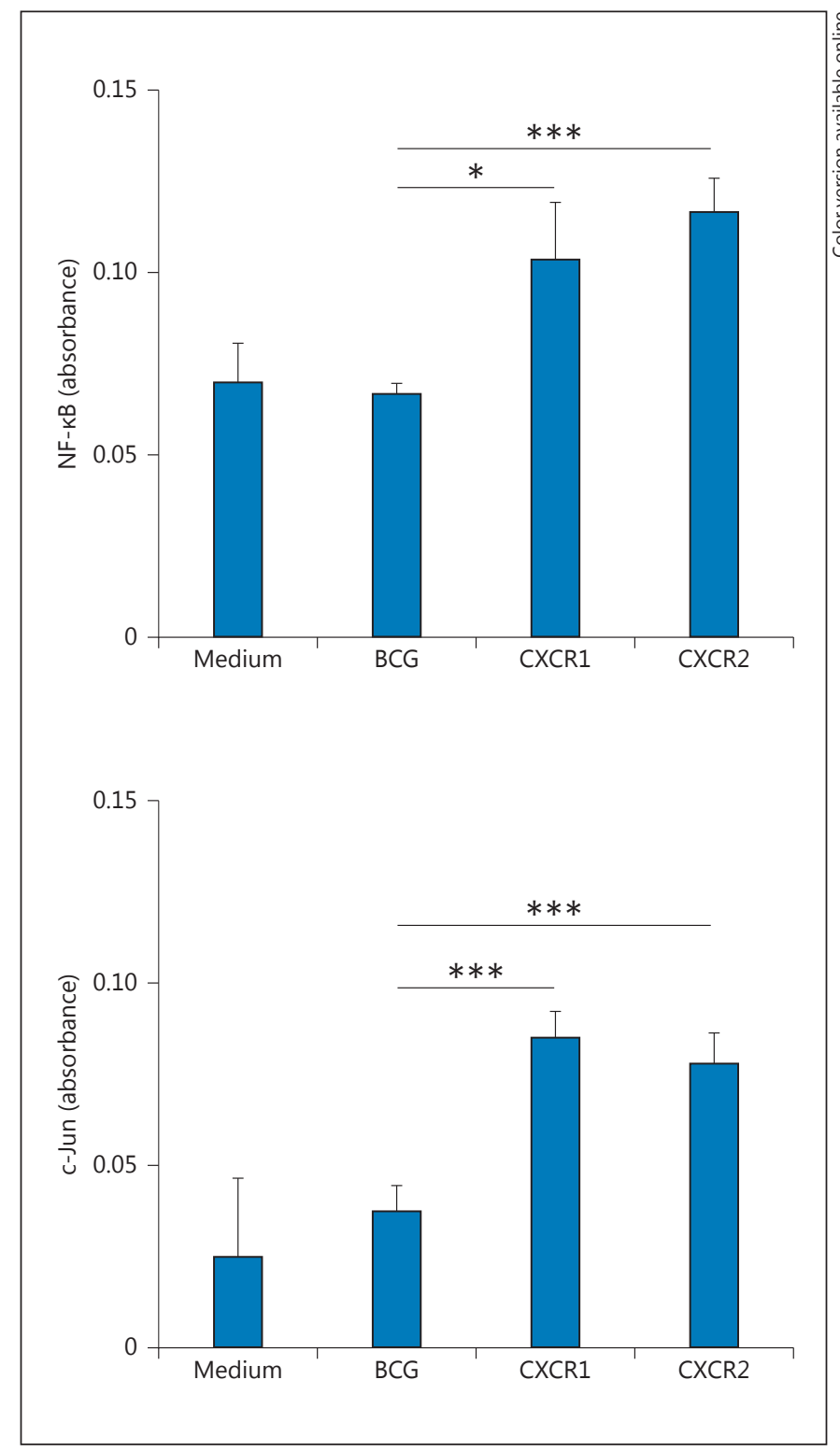

Fig. 5. Mycobacteria regulate NF- $\kappa \mathrm{B}$ and $c$-Jun through CXCR1 and CXCR2. We determined the impact of CXCR1 and CXCR2 blockage on mycobacteria-induced NF- $\kappa B$ and $c-J u n$ regulation. BCG infection did not affect epithelial NF- $\kappa$ B and AP-1 activation. However, the blockage of CXCR1 or CXCR2 prior to infection increased NF- $\kappa \mathrm{B}$ and $\mathrm{c}$-Jun protein levels compared to uninfected cells. Data are presented as mean \pm SEM of 3 separate experiments. * $p<0.05$; $^{* *} p<0.001$.

\section{Mycobacteria Regulate NF- $\kappa B$ and c-Jun through CXCR1 and CXCR2}

The data on NF- $\kappa$ B activation by pathogenic mycobacteria is still conflicting. BCG was previously shown to bypass NF- $\kappa B$ activation, but activate the signalling through

Increased Mucosal Rac1 Expression in TB

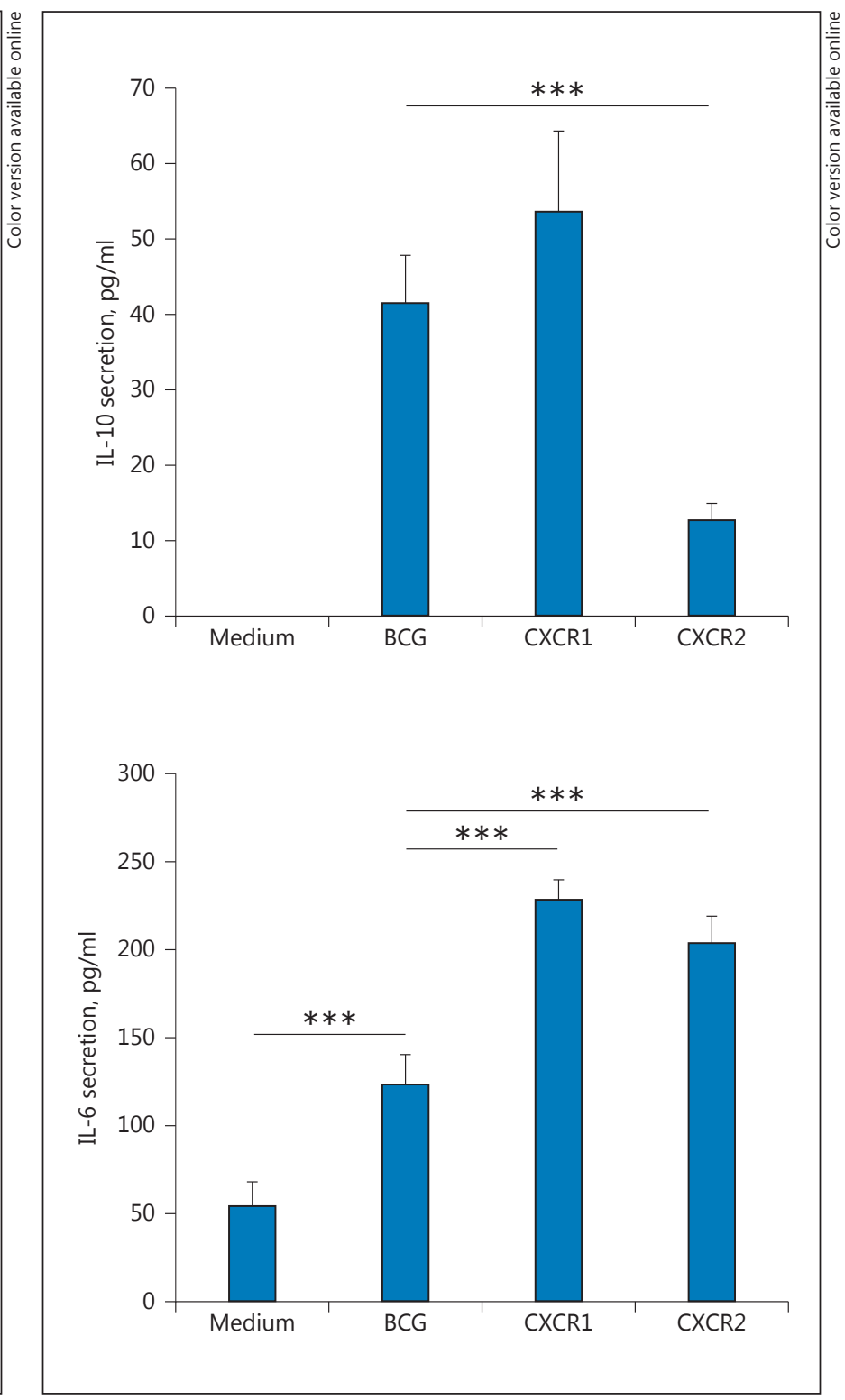

Fig. 6. Controlled epithelial cytokine secretion. Mycobacterial control of transcriptional factors was analysed as epithelial cytokine secretion. BCG infection of AECs induced significant IL-6 and IL-10 secretion. Blockage of CXCR1/2 prior to infection increased IL-6 secretion even further. IL-10 levels were decreased significantly by CXCR2 blockage, but not by CXCR1 antibodies. Data are presented as mean \pm SEM of 3 separate experiments. *** $p<0.001$.

ERK1/2 and cFos instead [40]. We could confirm that BCG did not increase the activation of NF- $\kappa$ B or AP-1 (c-Jun). Interestingly, blocking the epithelial GPCRs CXCR1 and CXCR2 prior to mycobacterial infection increased the NF$\kappa \mathrm{B}$ and c-Jun levels compared to uninfected cells (Fig. 5). 
Mycobacteria Control Epithelial Cytokine Secretion

Mycobacteria infection has been suggested to evoke the pro-inflammatory immune response in order to evade host immune responses. IL- 6 bridges innate and adaptive host immune responses, while the anti-inflammatory IL-10 suppresses inflammation and postpones the generation of adaptive immunity. Mycobacterial engagement of CXCR1 and CXCR2 to control cellular transcriptional factors was analysed as epithelial cytokine secretion. Infection of AECs induced significant IL- 6 and IL-10 secretion (Fig. 6). Blockage of CXCR1 or CXCR2 prior to infection increased IL-6 secretion even further $(p=0.0001 ; p=0.0004)$. However, IL-10 levels were significantly decreased by CXCR2 blockage compared to BCG-infected cells $(p=0.0001)$, while CXCR1 antibodies did not affect BCG-stimulated epithelial IL-10 production (Fig. 6). The treatment of uninfected cells with CXCR1 or CXCR2 antibodies did not affect IL-10 and IL-6 secretion (data not shown).

\section{Discussion}

Reprogramming of AECs could be beneficial for the development of vaccines and treatment strategies [4-6]. Evidence is now accumulating that innate immunity can "remember" previous exposure to a microorganism and could contribute to host defence against infection and vaccine-induced immunity. We found that BCG infection of mucosal AECs induced epithelial signalling pathways leading to actin remodelling and selective cytokine secretion. Actin cytoskeletal changes regulate junctional integrity that leads to disturbed barrier function during inflammation [35]. Mtb invasion of AECs is both receptor- and actin-mediated [41]. BCG is also known to invade AECs [18]; in this study, we show that the infection resulted in Rac1 up-regulation followed by altered epithelial actin distribution. Actin distribution by BCG infection requires $\mathrm{p} 38$ that is activated by phosphorylation at the T180/Y182 sites. Recently, macropinocytosis, in contrast to phagocytosis, was shown to lead to rapid elimination of mycobacteria, suggesting that the cytoskeletal mobilization could be involved in the initiation of the adaptive immune response [42]. A previous study showed that Mtb infection increased the oxidative stress in AECs through the $\mathrm{p} 38$-ERK-NF- $\kappa \mathrm{B}$ axis and led to the cytotoxicity of human lung epithelial cells $[43,44]$. Mtb could thus facilitate its own dissemination by compromising the epithelial lining. Contrary to this finding, our results demonstrated that BCG stimulated the MAPK pathway by signalling through the PYK2-p38-MAPK2JNK axis, pointing to a sustained epithelial barrier after BCG infection.

A wide variety of cellular processes are controlled by a complicated regulatory network consisting of positive and negative regulators. Additionally, post-translational modifications often affect points of regulation in a protein, which allows switching activities [45]. S15/S20 phosphorylation at $\mathrm{p} 53$ promotes the recruitment of transcriptional co-activators [46], while the phosphorylation of S46 is critical for p53-mediated induction of pro-apoptotic genes $[47,48]$. Phosphorylation of C-terminal S392 in response to ultraviolet light activates specific DNA binding through the stabilization of the p53 tetramer [49]. S392 phosphorylation was recently shown to promote cell survival by stabilizing p53 and enhancing its transcriptional activity [50]. Interestingly, inhibition of Rac1 resulted in decreased p53 S392 and S46 phosphorylation, possibly affecting transcription and cell survival in BCG-infected AECs. Our results indicate that BCG infection of AECs stimulate cell survival, which was also confirmed by the negative result of the cell death assay.

Bacterial adherence to cells is also known to trigger signal transduction events involving the G-proteins in actin polymerization, with the subsequent uptake of the bacteria [21, 37, 51]. GPCRs, such as CXCR1 and CXCR2, are important regulators in pulmonary diseases [52]. Previous research revealed that mycobacteria decrease epithelial cytokine production by manipulating these receptors [18], and active TB patients were found to have increased CXCR1 expression [53]. CXCR2 is important in the pathology of a wide diversity of chronic pulmonary diseases, and the modulation of CXCR2 function is considered as a possible therapeutic strategy [54]. Interestingly, blocking of these GPCRs prior to mycobacterial infection repealed the mycobacteria-induced actin redistribution and suppression of epithelial NF- $\kappa \mathrm{B}$ and $\mathrm{c}$-Jun, further supporting the theory that mycobacteria utilize GPCRs to manipulate cellular signalling [23]. GPCRs are also required for the activation of STAT, and STAT1 mutations were recently identified in patients with disseminated BCG infection $[55,56]$. The effect of STAT is to increase the transcriptional activity of quiescent genes and the transcription of less active genes [56]. BCG induced the phosphorylation of the transcription supporting STAT1 and STAT5b, while the STAT6 levels were reduced. Blocking CXCR1/R2 increased epithelial NF- $\kappa B$ and $c-J u n$ activation, and the secretion of IL- 6 
was increased. IL-6 is a multi-potent cytokine that acts in both pro- and anti-inflammatory ways. Exerting its pro-inflammatory qualities, IL-6 suppresses the development of regulatory $\mathrm{T}$ cells and favours the differentiation of effector T helper 17 cells during inflammation or infection [57]. Locally produced IL-6 could thus increase CD4+ $\mathrm{T}$ cell memory formation. Blocking CXCR2, but not CXCR1, decreased mycobacteria-induced IL-10 secretion. This cytokine modulates the anti-inflammatory mechanisms by targeting NF- $\kappa \mathrm{B}[58$, 59], which could have been the mechanism of suppressed transcriptional activity that we observed in our study. Impaired cellular activation and recruitment was previously related to increased IL-10 production and decreased CXCR2 expression during septic conditions $[60,61]$. In our study, blocking of epithelial CXCR2 reduced BCG-induced epithelial IL-10 secretion, possibly suggesting that CXCR2 signalling is important for BCG-induced IL-10 production.

It has been proposed that AECs and innate immune cells drive respiratory diseases [62]. AECs express MHCI/II [63], and the macropinocytosis of mycobacteria by AECs was recently shown to lead to rapid bacterial elimination [42]. The cytoskeletal mobilization due to macropinocytosis could thus be involved in antigen capture and presentation for incoming T cells [42]. More knowl- edge is needed on how mycobacteria manipulate cellular kinases and phosphatases, as these molecules constitute potential targets for future TB therapeutics [64]. We showed that the early event of mycobacterial AEC infection led to sustained manipulation of epithelial Racl and actin remodelling. Furthermore, our finding that mycobacteria utilized CXCR1 and CXCR2 to manipulate the inflammatory response clarifies the role of GPCRs in pulmonary disease, and possibly towards chronic disease [65]. Future vaccine strategies could thus be improved by targeting GPCRs.

\section{Acknowledgements}

This study was supported by a Research Scientist Grant from the Swedish Medical Research Council (2005-7364, 7364, 11550), the Crafoord Foundation, the Heart and Lung Foundation, the Evy and Gunnar Sandberg Foundation, and the Medical Faculty, Lund University, Sweden. The funders had no role in study design, data collection and analysis, decision to publish, or preparation of the manuscript.

\section{Disclosure Statement}

The authors have declared that no conflict of interests exists.

\section{References}

1 Garcia-Contreras L, Wong YL, Muttil P, Padilla D, Sadoff J, Derousse J, Germishuizen WA, Goonesekera S, Elbert K, Bloom BR, Miller R, Fourie PB, Hickey A, Edwards D: Immunization by a bacterial aerosol. Proc Natl Acad Sci USA 2008;105:4656-4660.

2 Barclay WR, Busey WM, Dalgard DW, Good RC, Janicki BW, Kasik JE, Ribi E, Ulrich CE, Wolinsky E: Protection of monkeys against airborne tuberculosis by aerosol vaccination with bacillus Calmette-Guérin. Am Rev Respir Dis 1973;107:351-358.

3 Aronson NE, Santosham M, Comstock GW, Howard RS, Moulton LH, Rhoades ER, Harrison LH: Long-term efficacy of BCG vaccine in American Indians and Alaska natives: a 60year follow-up study. JAMA 2004;291:20862091.

4 Aaby P, Benn CS: Saving lives by training innate immunity with bacille Calmette-Guérin vaccine. Proc Natl Acad Sci USA 2012;109: 17317-17318.
5 Blok BA, Arts RJ, van Crevel R, Benn CS, Netea MG: Trained innate immunity as underlying mechanism for the long-term, nonspecific effects of vaccines. J Leukoc Biol 2015;98: 347-356.

6 Lerm M, Netea MG: Trained immunity: a new avenue for tuberculosis vaccine development. J Intern Med 2016;279:337-346.

7 Netea MG, Latz E, Mills KH, O’Neill LA: Innate immune memory: a paradigm shift in understanding host defense. Nat Immunol 2015;16:675-679.

8 Castro-Garza J, King CH, Swords WE, Quinn FD: Demonstration of spread by Mycobacterium tuberculosis bacilli in a549 epithelial cell monolayers. FEMS Microbiol Lett 2002;212: 145-149.

9 Harriff MJ, Cansler ME, Toren KG, Canfield ET, Kwak S, Gold MC, Lewinsohn DM: Human lung epithelial cells contain mycobacterium tuberculosis in a late endosomal vacuole and are efficiently recognized by $\mathrm{CD} 8(+) \mathrm{T}$ cells. PLoS One 2014;9:e97515.
10 van der Meer JW, Joosten LA, Riksen N, Netea MG: Trained immunity: a smart way to enhance innate immune defence. Mol Immunol 2015;68:40-44.

11 Fritz C, Maass S, Kreft A, Bange FC: Dependence of Mycobacterium bovis BCG on anaerobic nitrate reductase for persistence is tissuespecific. Infect Immun 2002;70:286-291.

12 Hutter B, Dick T: Analysis of the dormancyinducible Nark2 promoter in Mycobacterium bovis BCG. FEMS Microbiol Lett 2000;188: 141-146.

13 Lim A, Eleuterio M, Hutter B, Murugasu-Oei B, Dick T: Oxygen depletion-induced dormancy in Mycobacterium bovis BCG. J Bacteriol 1999;181:2252-2256.

14 Murugasu-Oei B, Dick T: Bactericidal activity of nitrofurans against growing and dormant Mycobacterium bovis BCG. J Antimicrob Chemother 2000;46:917-919. 
15 Garcia-Perez BE, Mondragon-Flores R, Luna-Herrera J: Internalization of Mycobacterium tuberculosis by macropinocytosis in nonphagocytic cells. Microb Pathog 2003;35:4955.

16 Garcia-Perez BE, Castrejon-Jimenez NS, Luna-Herrera J: The role of non-phagocytic cells in mycobacterial infections; in Cardona PJ (ed): Understanding Tuberculosis - Analyzing the Origin of Mycobacterium tuberculosis Pathogenicity, chapt 6. Rijeka, InTech, 2012, pp 149-178.

17 Torrelles JB, Azad AK, Henning LN, Carlson TK, Schlesinger LS: Role of C-type lectins in mycobacterial infections. Curr Drug Targets 2008;9:102-112.

18 Hakansson G, Lutay N, Andersson M, Hallgren $\mathrm{O}$, Westergren-Thorsson G, Svensson M, Godaly G: Epithelial G protein-coupled receptor kinases regulate the initial inflammatory response during mycobacterial infection. Immunobiology 2013;218:984-994.

19 Fiorentini C, Falzano L, Travaglione S, Fabbri A: Hijacking Rho GTPases by protein toxins and apoptosis: molecular strategies of pathogenic bacteria. Cell Death Differ 2003;10:147152.

20 Zigmond SH, Joyce M, Borleis J, Bokoch GM, Devreotes PN: Regulation of actin polymerization in cell-free systems by GTPgammaS and Cdc42. J Cell Biol 1997;138:363-374.

21 Mounier J, Laurent V, Hall A, Fort P, Carlier MF, Sansonetti PJ, Egile C: Rho family GTPases control entry of Shigella flexneri into epithelial cells but not intracellular motility. J Cell Sci 1999;112:2069-2080.

22 Ferro E, Goitre L, Retta SF, Trabalzini L: The interplay between ROS and Ras GTPases: physiological and pathological implications. J Signal Transduct 2012;2012:365769.

23 Guo AK, Hou YY, Hirata H, Yamauchi S, Yip AK, Chiam KH, Tanaka N, Sawada Y, Kawauchi K: Loss of p53 enhances NF- $\kappa B$-dependent lamellipodia formation. J Cell Physiol 2014; 229:696-704.

24 Blander JM, Medzhitov R: Regulation of phagosome maturation by signals from tolllike receptors. Science 2004;304:1014-1018.

25 Doyle SE, O'Connell RM, Miranda GA, Vaidya SA, Chow EK, Liu PT, Suzuki S, Suzuki N, Modlin RL, Yeh WC, Lane TF, Cheng G: Tolllike receptors induce a phagocytic gene program through p38. J Exp Med 2004;199:8190.

26 Mathieu J: Interactions between autophagy and bacterial toxins: targets for therapy? Toxins (Basel) 2015;7:2918-2958.

27 Desai M, Fang R, Sun J: The role of autophagy in microbial infection and immunity. Immunotargets Ther 2015;4:13-26.

28 Qian Y, Chen X: Tumor suppression by $\mathrm{p} 53$ : making cells senescent. Histol Histopathol 2010;25:515-526.
29 Baltierra-Uribe SL, Garcia-Vasquez Mde J, Castrejon-Jimenez NS, Estrella-Pinon MP, Luna-Herrera J, Garcia-Perez BE: Mycobacteria entry and trafficking into endothelial cells. Can J Microbiol 2014;60:569-577.

30 Kaushal D, Foreman TW, Gautam US, Alvarez X, Adekambi T, Rangel-Moreno J, Golden NA, Johnson AM, Phillips BL, Ahsan MH, Russell-Lodrigue KE, Doyle LA, Roy CJ, Didier PJ, Blanchard JL, Rengarajan J, Lackner AA, Khader SA, Mehra S: Mucosal vaccination with attenuated Mycobacterium tuberculosis induces strong central memory responses and protects against tuberculosis. Nat Commun 2015;6:8533.

31 Fine KL, Metcalfe MG, White E, Virji M, Karls RK, Quinn FD: Involvement of the autophagy pathway in trafficking of Mycobacterium tuberculosis bacilli through cultured human type II epithelial cells. Cell Microbiol 2012;14:1402-1414.

32 Randall PJ, Hsu NJ, Quesniaux V, Ryffel B, Jacobs M: Mycobacterium tuberculosis infection of the "non-classical immune cell." Immunol Cell Biol 2015;93:789-795.

33 Snewin VA, Gares MP, Gaora PO, Hasan Z, Brown IN, Young DB: Assessment of immunity to mycobacterial infection with luciferase reporter constructs. Infect Immun 1999;67: 4586-4593.

34 Chung CY, Lee S, Briscoe C, Ellsworth C, Firtel RA: Role of Rac in controlling the actin cytoskeleton and chemotaxis in motile cells. Proc Natl Acad Sci USA 2000;97:5225-5230.

35 Finlay BB, Cossart P: Exploitation of mammalian host cell functions by bacterial pathogens. Science 1997;276:718-725.

36 Osmond RI, Crouch MF, Dupriez VJ: An emerging role for kinase screening in GPCR drug discovery. Curr Opin Mol Ther 2010;12: 305-315.

37 Fiorentini C, Falzano L, Fabbri A, Stringaro A, Logozzi M, Travaglione S, Contamin S, Arancia G, Malorni W, Fais S: Activation of Rho GTPases by cytotoxic necrotizing factor 1 induces macropinocytosis and scavenging activity in epithelial cells. Mol Biol Cell 2001; 12:2061-2073.

38 Mounier N, Arrigo AP: Actin cytoskeleton and small heat shock proteins: how do they interact? Cell Stress Chaperones 2002;7:167-176.

39 Dupuis S, Dargemont C, Fieschi C, Thomas$\sin$ N, Rosenzweig S, Harris J, Holland SM, Schreiber RD, Casanova JL: Impairment of mycobacterial but not viral immunity by a germline human Stat1 mutation. Science 2001;293:300-303.

40 Lutay N, Hakansson G, Alaridah N, Hallgren O, Westergren-Thorsson G, Godaly G: Mycobacteria bypass mucosal NF- $\mathrm{KB}$ signalling to induce an epithelial anti-inflammatory IL-22 and IL-10 response. PLoS One 2014;9:e86466.

41 Bermudez LE, Goodman J: Mycobacterium tuberculosis invades and replicates within type II alveolar cells. Infect Immun 1996;64: 1400-1406.
42 Bosedasgupta S, Pieters J: Inflammatory stimuli reprogram macrophage phagocytosis to macropinocytosis for the rapid elimination of pathogens. PLoS Pathog 2014;10:e1003879.

43 Shin SJ, Chang CF, Chang CD, McDonough SP, Thompson B, Yoo HS, Chang YF: In vitro cellular immune responses to recombinant antigens of Mycobacterium avium subsp. paratuberculosis. Infect Immun 2005;73: 5074-5085.

44 Li H, Li Q, Yu Z, Zhou M, Xie J: Mycobacterium tuberculosis PE13 (Rv1195) manipulates the host cell fate via $\mathrm{p} 38$-ERK-NF- $\mathrm{KB}$ axis and apoptosis. Apoptosis 2016;21:795-808.

45 Retzlaff M, Stahl M, Eberl HC, Lagleder S, Beck J, Kessler H, Buchner J: Hsp90 is regulated by a switch point in the C-terminal domain. EMBO Rep 2009;10:1147-1153.

46 Toledo F, Wahl GM: Regulating the p53 pathway: in vitro hypotheses, in vivo veritas. Nat Rev Cancer 2006;6:909-923.

47 Raver-Shapira N, Marciano E, Meiri E, Spector Y, Rosenfeld N, Moskovits N, Bentwich Z, Oren M: Transcriptional activation of Mir34a contributes to p53-mediated apoptosis. Mol Cell 2007;26:731-743.

48 Olsson A, Manzl C, Strasser A, Villunger A: How important are post-translational modifications in p53 for selectivity in target-gene transcription and tumour suppression? Cell Death Differ 2007;14:1561-1575.

49 Matsumoto M, Furihata M, Ohtsuki Y: Posttranslational phosphorylation of mutant p53 protein in tumor development. Med Mol Morphol 2006;39:79-87.

50 Retzlaff M, Rohrberg J, Kupper NJ, Lagleder S, Bepperling A, Manzenrieder F, Peschek J, Kessler H, Buchner J: The regulatory domain stabilizes the p53 tetramer by intersubunit contacts with the DNA binding domain. J Mol Biol 2013;425:144-155.

51 Yang C, Huang M, DeBiasio J, Pring M, Joyce M, Miki H, Takenawa T, Zigmond SH: Profilin enhances Cdc42-induced nucleation of actin polymerization. J Cell Biol 2000;150: 1001-1012.

52 Barnes PJ, Chung KF, Page CP: Inflammatory mediators of asthma: an update. Pharmacol Rev 1998;50:515-596.

53 Alaridah N, Winqvist N, Hakansson G, Tenland E, Ronnholm A, Sturegard E, Bjorkman P, Godaly G: Impaired CXCR1-dependent oxidative defence in active tuberculosis patients. Tuberculosis (Edinb) 2015;95:744750 .

54 Rennard SI, Dale DC, Donohue JF, Kanniess F, Magnussen H, Sutherland ER, Watz H, Lu S, Stryszak P, Rosenberg E, Staudinger H: CXCR2 antagonist MK-7123. A phase 2 proof-of-concept trial for chronic obstructive pulmonary disease. Am J Respir Crit Care Med 2015;191:1001-1011.

Alaridah et al. 
55 O'Shea JJ, Holland SM, Staudt LM: Jaks and Stats in immunity, immunodeficiency, and cancer. N Engl J Med 2013;368:161-170.

56 Levy DE, Darnell JE Jr: Stats: transcriptional control and biological impact. Nat Rev Mol Cell Biol 2002;3:651-662.

57 Scheller J, Chalaris A, Schmidt-Arras D, Rose-John S: The pro- and anti-inflammatory properties of the cytokine interleukin-6. Biochim Biophys Acta 2011;1813:878-888.

58 de Waal Malefyt R, Abrams J, Bennett B, Figdor CG, de Vries JE: Interleukin 10 (IL-10) inhibits cytokine synthesis by human monocytes: an autoregulatory role of IL-10 produced by monocytes. J Exp Med 1991;174: 1209-1220.
59 Bhattacharyya S, Sen P, Wallet M, Long B, Baldwin AS Jr, Tisch R: Immunoregulation of dendritic cells by IL-10 is mediated through suppression of the PI3K/Akt pathway and of IkappaB kinase activity. Blood 2004;104: 1100-1109.

60 Goodman R, Cummings C, Frevert C, Quan J, Martin T: Functional significance of CXCR2 downregulation on neutrophils from patients with severe sepsis. Chest 1999;116:111S$112 S$.

61 Andrade EB, Alves J, Madureira P, Oliveira L, Ribeiro A, Cordeiro-da-Silva A, CorreiaNeves M, Trieu-Cuot P, Ferreira P: TLR2-induced IL-10 production impairs neutrophil recruitment to infected tissues during neonatal bacterial sepsis. J Immunol 2013;191: 4759-4768.
62 Holtzman MJ, Byers DE, Alexander-Brett J, Wang X: The role of airway epithelial cells and innate immune cells in chronic respiratory disease. Nat Rev Immunol 2014;14:686-698.

63 Cunningham AC, Zhang JG, Moy JV, Ali S, Kirby JA: A comparison of the antigen-presenting capabilities of class II MHC-expressing human lung epithelial and endothelial cells. Immunology 1997;91:458-463.

64 Lechartier B, Rybniker J, Zumla A, Cole ST: Tuberculosis drug discovery in the post-postgenomic era. EMBO Mol Med 2014;6:158168.

65 Inghammar M, Ekbom A, Engstrom G, Ljungberg B, Romanus V, Lofdahl CG, Egesten A: COPD and the risk of tuberculosis - a population-based cohort study. PLoS One 2010;5:e10138. 